\title{
Orientation Log Chart
}

An orientation log is not synonymous with competency validation. This form may be used to assist the preceptor in documenting experiences that the orienting nurse encountered.

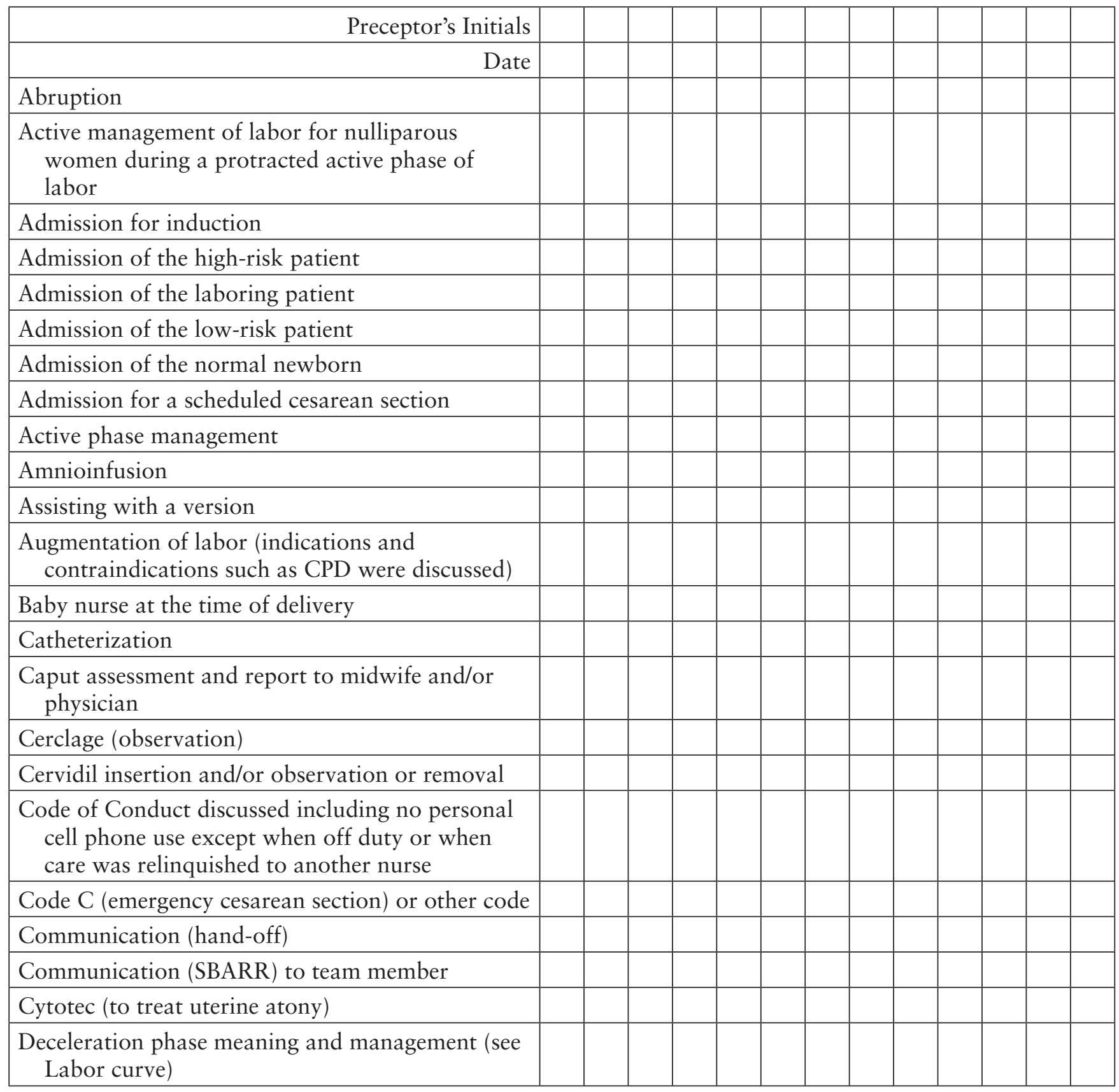




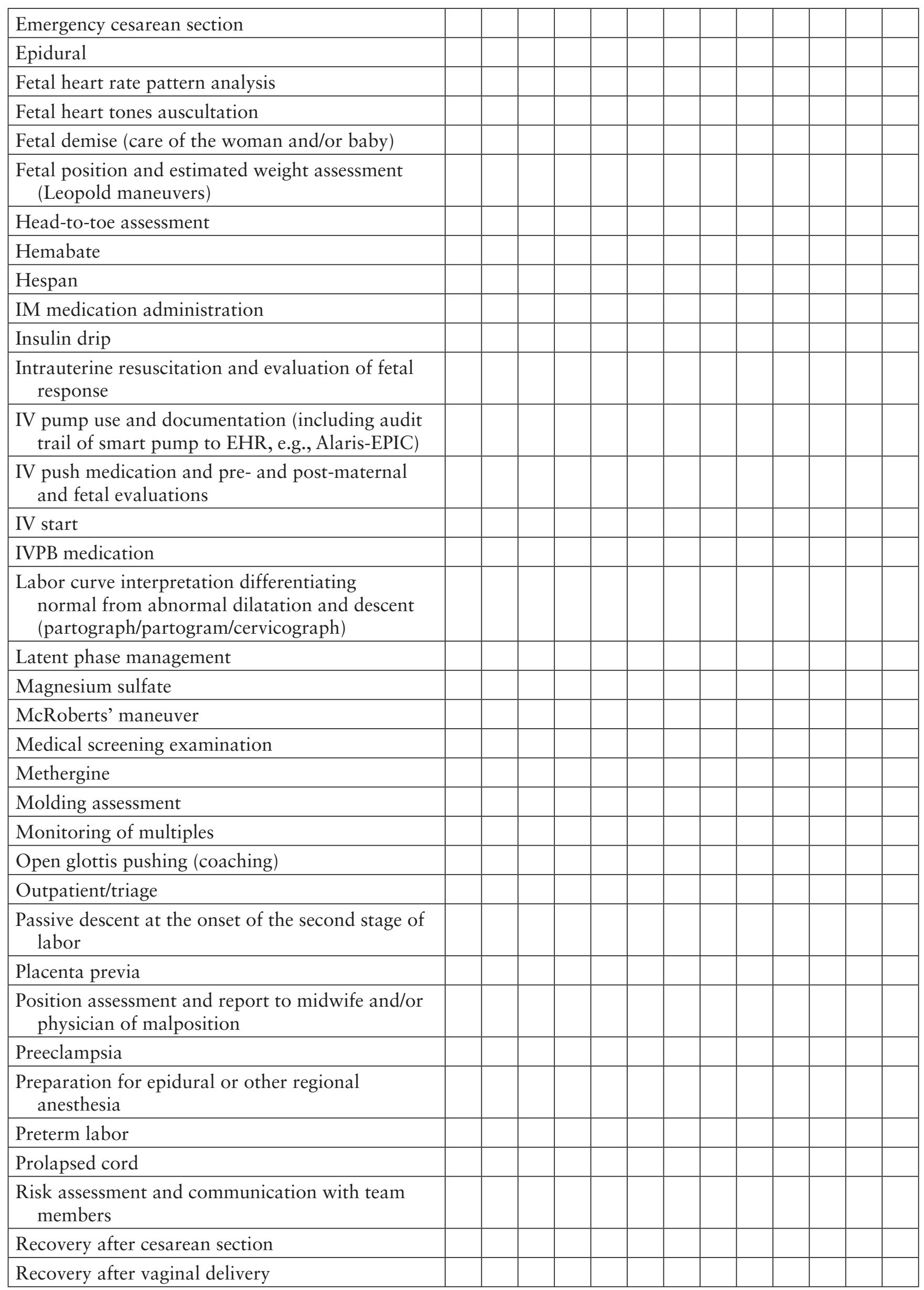




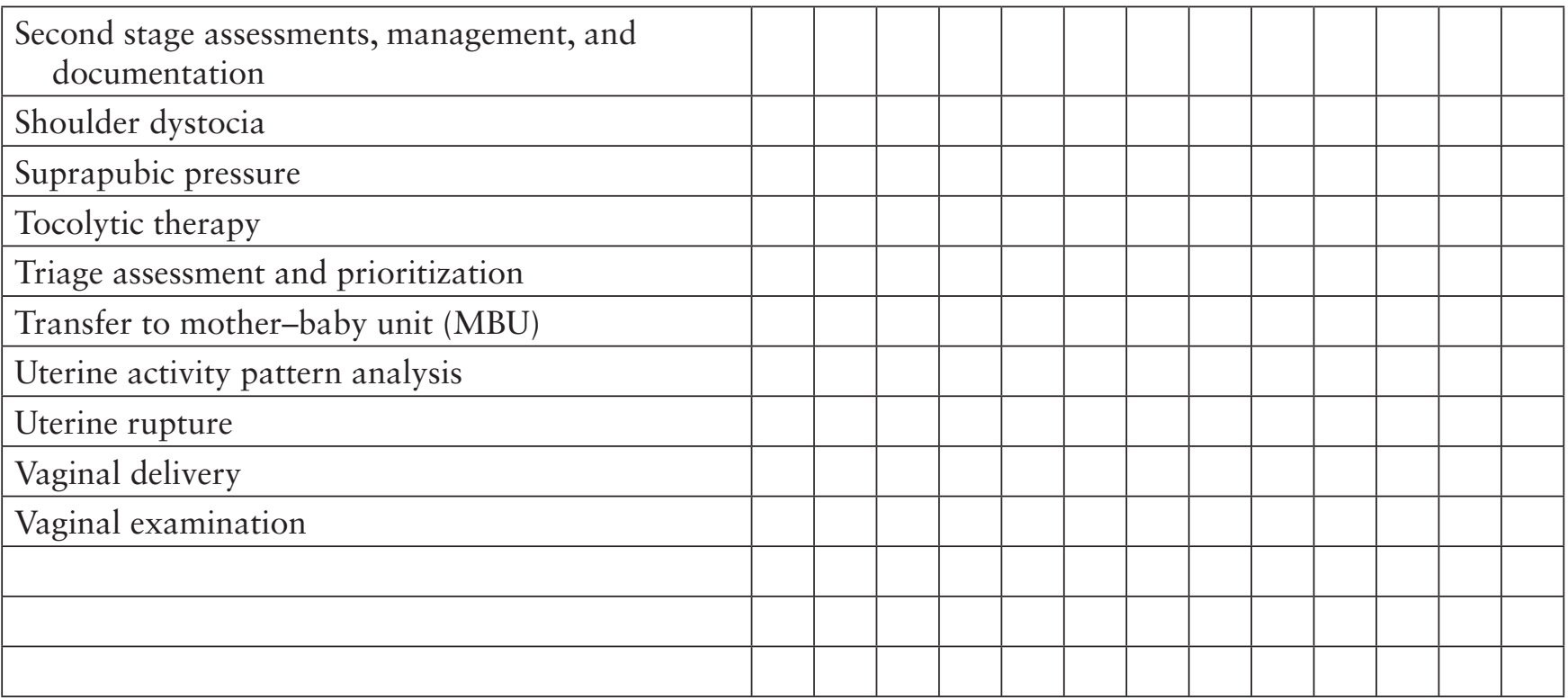

Preceptor's Initials Signature

Preceptor's Initials Signature

Preceptor's Initials Signature

Preceptor's Initials Signature 